\title{
The Effects of Maternal Emotion Socialization of Disappointment on Prosocial Behavior in Preschool Aged Children
}

\author{
Alexandria Svolos
}

Follow this and additional works at: https://researchrepository.wvu.edu/etd

\section{Recommended Citation}

Svolos, Alexandria, "The Effects of Maternal Emotion Socialization of Disappointment on Prosocial Behavior in Preschool Aged Children" (2018). Graduate Theses, Dissertations, and Problem Reports. 6749. https://researchrepository.wvu.edu/etd/6749

This Thesis is protected by copyright and/or related rights. It has been brought to you by the The Research Repository @ WVU with permission from the rights-holder(s). You are free to use this Thesis in any way that is permitted by the copyright and related rights legislation that applies to your use. For other uses you must obtain permission from the rights-holder(s) directly, unless additional rights are indicated by a Creative Commons license in the record and/ or on the work itself. This Thesis has been accepted for inclusion in WVU Graduate Theses, Dissertations, and Problem Reports collection by an authorized administrator of The Research Repository @ WVU. For more information, please contact researchrepository@mail.wvu.edu. 
The Effects of Maternal Emotion Socialization of Disappointment on Prosocial Behavior in Preschool Aged Children

\author{
Alexandria Svolos \\ Thesis Submitted \\ to the Learning Sciences and Human Development \\ at West Virginia University \\ in partial fulfillment of the requirements for the degree of \\ Master of Arts in \\ Educational Psychology with an emphasis in Child Development and Family Studies
}

Amy Root, Ph.D., Chair

Suzanne Hartman, Ph.D.

Amy Gentzler, Ph.D.

College of Education and Human Services

Morgantown, West Virginia

2018

Keywords: Maternal emotion socialization, prosocial behavior, gender, preschool Copyright 2018 Alexandria Svolos 


\begin{abstract}
The Effects of Maternal Emotion Socialization of Disappointment on Prosocial Behavior in

Preschool Aged Children
\end{abstract}

\begin{abstract}
Alexandria Svolos
The purpose of the present study was to examine the maternal socialization of disappointment and its impact on prosocial behavior. In a structured laboratory observation, sixty-five preschool aged children and their mothers underwent a disappointment task. The mothers $(M=34.27$ years) completed two questionnaires to assess response to disappointment and children's frequency to prosocial behavior. Maternal observed behaviors of negative affect were positively associated with higher maternal reports of prosocial behavior in children. Also, mothers who reported using problem-focused responses to children's disappointment reported having children who were more prosocial. There were also significant gender differences. Mothers of sons only had significant findings when using problem-focused responses. While mothers of daughters saw the same results yielded from the full sample. Mothers also spent more time engaged with daughters during times of disappointment than with sons. These findings take previous research one step further by focusing on a new aspect of disappointment and by examining the socialization of a specific emotion. The findings generated from this study can be used in real world applications to help mothers teach children to perspective take and be more prosocial towards others.
\end{abstract}


Table of Contents

Abstract

Table of Contents

List of Tables

Introduction

Statement of the Problem

Review of Related Literature

Statement of the Hypothesis

Method

Participants

Procedure

Measures

Results

Discussion

References

Appendix A

Appendix B

Appendix C
19

22

32

44

47

Page

ii

iii

iv

1

3

5

14

15

15

16

16

55 


\section{List of Tables}

Table

Page

1.1 Descriptive Statistics of Negative Affect,

Positive Affect, Engagement, Praise,

Intrusiveness, Problem-focused Response,

Emotion-focused Response, Emotion-

expressive Response, Punishment Response, Minimization Response, Distress response, and Prosocial and Empathy

1.2 Descriptive Statistics of Negative Affect,

Positive Affect, Engagement, Praise,

Intrusiveness, Problem-focused Response,

Emotion-focused Response, Emotion-

expressive Response, Punishment Response, Minimization Response, Distress response, and Prosocial and Empathy for Males and Females

2. Full Sample Correlations for all Measures

3. Correlation for Male and Female 
The Effects of Maternal Emotion Socialization of Disappointment on Prosocial Behavior in Preschool Aged Children

Overview

Prosocial behaviors in preschool aged children are an important part of social and emotional development. Prosocial behaviors, including kindness (Hastings, McShane, Parker, \& Ladha, 2007), helping others without reward (Choukas-Bradley, Giletta, Cohen, \& Prinstein, 2015), and empathy (Krevans \& Gibbs, 1996) are influenced by many factors including maternal emotion socialization, parenting style, and gender. Maternal emotion socialization is a concept in child development that contributes to many positive or negative child outcomes. Emotion socialization, or the process of conveying to children the appropriate ways to express emotional actions, reactions, and behaviors, affect the development of prosocial behaviors (Denham, Bassett, \& Wyatt, 2015). Few studies have focused on the specific socialization of disappointment and its relation to future prosocial behaviors. The socialization of disappointment may influence future prosocial behaviors. Cole, Zahn-Waxler, and Smith (1994) found that when faced with disappointment (i.e. receiving an undesirable toy) boys and at-risk preschoolers had more difficultly masking their disappointment and showed increased anger. Such negative outcomes to disappointment are slightly reduced when the child can express their disappointment to their mother (Cole, 1984) or are in the presence of a friendly yet unfamiliar adult (Cole, et al., 1994). These findings indicate that the periods after disappointment are an opportunity to teach children appropriate responses to disappointing situations. It is important for researchers to study this connection for multiple reasons. If disappointment does influence prosocial behaviors this knowledge can be used in all settings with children to promote such behaviors. It is important for 
individuals to be prosocial because it prompts them to show compassion, empathy, and kindness, which may positively influence peer relationships.

\section{Justification of Study}

Previous studies have examined the relationship between prosocial behaviors and emotion socialization (Krevans \& Gibbs, 1996; Taylor, Eisenberg, Spinard, Eggum, \& Sulik, 2013). However, very few studies have looked at the socialization of specific emotions, including disappointment, and the relationship between the socialization of specific emotions and prosocial behavior. Previous studies have focused on the influence of general parenting practices, emotion socialization (Chaplin, Cole \& Zahn-Waxler, 2005; Scrimegeour, Blandon, Stifer, \& Buss, 2013), and gender (Hastings, Rubin, \& DeRose, 2005; Newland \& Crnic, 2011) in the development of prosocial behavior. These studies suggest that emotion socialization and prosocial behavior are linked (Hastings et al., 2007; Scrimegeour, Davis, \& Buss, 2015). It is necessary to look specifically at disappointment because disappointment is likely to provoke empathy and prosocial behaviors in children (Patrick \& Gibbs, 2007). Preschool aged children are typically aged three to five and are a good age group to study the presented research question. During this time, children are being socialized by parents, family, teachers, peers, and many other agents. Also, children are starting to develop new complex emotions, like disappointment. Based on the Facial Action Coding System (FACS) (Ekman \& Friesen, 1978), children who are disappointment may lower their brows, tighten or press their lips or wrinkle their noses. They may also become aggressive, quiet, or vocalize their disappointment (Cole, Zhan-Waxler, \& Smith, 1994). Therefore, it seems reasonable to further examine links between maternal emotion socialization of disappointment and prosocial behavior in preschool aged children. 
Prosocial behavior is part of the foundation of social development that is influenced by many factors. The current study will focus on the relations of emotion socialization and gender on prosocial behavior. Supportive emotion socialization can positively contribute to multiple child outcomes. Supportive emotion socialization can be categorized as encouragement, tolerance, comfort, acceptance and empathy of children's emotion expressiveness, knowledge, and regulation (Denham et al., 2015). Nonsupportive emotion socialization can be described as punitive or dismissive responses to a child's emotion (Denham et al., 2015). Emotion socialization can support the development of prosocial behavior by providing appropriate parental socialization, which includes being assertive and engaged, and providing best-fit childrearing (Hastings et al., 2007; Padilla-Walker, Carlo, Christensen, \& Yorgason, 2012). In turn, prosocial behavior is linked to positive peer interactions (Choukas-Bradley et al., 2015), social adjustment (Dunn, Deater-Deckard, Pickering, \& O’Connor, 1998), and social competence (Altay \& Gure, 2012). Indeed, prosocial behavior is an important aspect of children's development, and understanding the factors related to it are important to study.

\section{Statement of the Problem}

As previously mentioned, there is plenty of research on emotion socialization. However, most previous research focuses on the negative outcomes of socialization including anxiety (Oppenheimer et al., 2016), depression (Shortt et al., 2016), and behavior problems (Breaux, Harvey, \& Lugo-Candelas, 2016). This study will focus on the positive outcomes associated with emotion socialization, namely prosocial behavior. There is existing research linking prosocial behavior to emotion socialization (van der Pol et al., 2016), as well as literature linking parenting and prosocial behavior (London Bocknek, Brophy-Herb, \& Banerjee, 2009) and the relations between gender and prosocial behavior (Newton, Laible, Carlo, Steele, \& McGinley, 2014). 
However, examining the relations between the socialization of disappointment and prosocial behavior will provide new information by expanding our knowledge of what helps form prosociality, and the influence disappointment socialization has on children's development. This is important because the more that is known about prosocial behavior development the better we can promote such positive behaviors and create lasting behavior skills. Understanding disappointment is also important to the field. Currently, most research on disappointment is focused on parents' discipline and how the use or expression of disappointment influences discipline (Patrick \& Gibbs, 2007). Previous studies have not focused on parents' reactions to children's expression of disappointment and have only examined parents' own expression of disappointment. This gap in the literature calls for more research based on the socialization of the emotion, not just how parents use disappointment as punishment or to promote prosocial behaviors. Additionally, how parents respond to their child's disappointment may help promote prosocial behaviors from the child. Parents that focus on how children express and deal with disappointment can interfere with their social interactions and prompt their child to engage in more prosocial behaviors. Presumably, children who express and deal with disappointment in an appropriate way will have more interactions. The appropriate coping and more frequent interactions can lead children to display more prosocial behaviors.

\section{Purpose of the Study}

The purpose of this study is to examine the link between maternal emotion socialization and prosocial behavior; specifically, the aim of this study was to look at how the socialization of disappointment relates to prosocial behavior in preschool aged children. This study will contribute to the field by showing the connection and influence that specific emotions can have 
on prosocial behavior. The focus of this study will be to look at maternal emotion socialization of disappointment and prosocial behavior.

\section{Literature Review}

Prosocial behavior is an important aspect of emotional and social development. Displaying prosocial behaviors, such as agreeableness and kindness, can lead to positive peer interactions (Hastings et al., 2007), better overall adjustment (Dunn et al., 1998), and positive parenting style (Padilla-Walker et al., 2012). Children who display prosocial behaviors also have better peer relationships (Flynn, Ehrenreich, Beron, \& Underwood, 2015), less internalizing and externalizing problems (Dunn et al., 1998), and greater empathy (Krevans \& Gibbs, 1996). Indeed, prosocial behaviors provide a foundation for future gains in social and emotional development. Prosocial behaviors are rooted in kindness, empathy, and compassion. Being prosocial is linked to more positive social interactions with peers throughout the childhood and adolescences years (Choukas-Bradley et al., 2015). Those interactions aid in development because they allow for more learning opportunities through social experiences, engagement in more prosocial behaviors, and volunteering (Choukas-Bradley, et al., 2015). Prosocial behavior is socialized by parents (Hastings et al., 2005), and is also affected by child characteristics, including gender (Hastings et al., 2007).

Parents influence the development of prosocial behaviors. The type of parenting used can affect a child's display of prosocial behaviors. For instance, authoritative parenting, defined as a style that is warm and positive but allows parents to provide appropriate amounts of control and independence of their child (Baumrind, 1966), is linked to the development of prosocial behaviors (Hastings et al., 2007). Children whose parents use authoritative parenting practices 
may benefit more from socialization (Hastings et al., 2005) due to consistent, clear, and positive parenting practices. This may help convey to children the ideal ways to behave as evidenced in studies linking authoritative parenting and prosocial behavior. For instance, authoritative parenting has been linked to greater sharing behaviors with peers (Hastings et al., 2007). Similarly, Padilla-Walker, Carlo, Christenson, and Yorgason (2012) found that eleven- to fifteen-year-olds who engaged in more prosocial behaviors had parents who used an authoritative parenting style.

Other parenting behaviors have also been linked to prosocial behavior. For instance, Day and Padilla-Walker (2009) reported in a study on children ages ten-fourteen that parents' connectedness and involvement were linked to the amount of prosocial behavior in children. Connectedness refers to the parent-child bond and social connection (Day \& Padillia-Walker, 2009). While parental involvement refers to a parent's engagement in all aspects of a child's life (Day \& Padillia-Walker, 2009). Mothers' involvement and connectedness were positively related to prosocial development (Day \& Padillia-Walker, 2009). Additionally, in another longitudinal study, maternal sensitivity and modeling during the preschool years were positively predictive of children's prosociality during middle childhood (Newton et al., 2014). Maternal sensitivity is measured by accurate, timely, supportive, and warm responses to a child's needs (Newton et al., 2014). Whereas maternal modeling is when children behave in an identical or similar way they have seen their mother behave (Newton et al., 2014). The maternal sensitivity and modeling promote prosocial behavior by a mother's sensitive response to her child and the child modeling that response. A sensitive response from a mother, especially when experiencing an emotion like disappointment, may reduce some stress for a child and help them cope with their situation 
(Cassidy, 1994; Gunnar, 2000). Observing these sensitive behaviors from their mothers may encourage children to model them and use prosocial behaviors in their own interactions.

The quality of mother-child relationships has also been examined as they contribute to prosocial behavior. Mother-child relationships, like other relationships, are defined as the bond between the members of the relationship. In research, the quality of relationship is often examined. To assess relationship quality parental warmth (affection and support), involvement (interest and solicitude), and responsiveness (the time it takes to react) are typically considered (Hastings et al., 2007; Pastorelli et al., 2016). There are numerous scales to assess quality as well, including the Parental Acceptance-Rejection/Control Questionnaire (Pastorelli et al., 2016). To have a high-quality relationship, both parties must consider the relationship to be warm, responsive, and engaged. Pastorelli and colleagues (2016) found a positive and significant relationship between early prosocial behaviors and later high quality of mother-child relationship. These findings allow us to assume that mothers and children who view the children as more prosocial are more likely to be involved in a high-quality mother-child relationship (Pastorelli et al., 2016). High-quality relationships foster positive parenting and parental aspects that promote prosocial behavior, including warmth and involvement (Pastorelli et al., 2016). One factor of a high-quality relationship, that greatly benefits children, is a secure attachment. Children who have a secure attachment with a caregiver have more, closer, and better relationships with other individuals, including peers (Bowlby, 1973). Through this secure attachment, children learn that the world can be explored safely. Having this feeling of safety allows children to interact in a more positive way, setting the stage for prosocial behaviors (Bowlby, 1973). And previous studies on adolescents show that secure attachment is associated with prosocial behavior (Laible, Carlo, \& Roesch, 2004). 


\section{Emotion Socialization and Prosocial Behavior}

One area of parenting that may be particularly relevant to the development of prosocial behavior is emotion socialization. Emotion socialization is a learning experience that children face daily (Denham et al., 2015). Emotion socialization is a component of parenting style and practices including parental emotional reactions, emotion talk, emotion modeling, and emotion regulation (Denham et al., 2015; Premo \& Kiel, 2015); better put, emotion socialization is the process by which children learn the ways to express emotions, how they understand emotions, and how they learn about socially appropriate ways to regulate emotions (Denham et al., 2015) The socialization of emotions can lead to positive and negative outcomes. Non-supportive socialization, which includes discouragement, minimizing, and dismissing emotions, has been linked to internalizing and externalizing problems (Denham et al., 2015; Newland \& Crnic, 2011). Supportive socialization, including tolerance, encouragement, and validation of emotions (Denham et al., 2015), has been linked to better emotion regulation (Rodgers, Halberstadt, Castro, MacCormack, \& Garrett-Peters, 2015), and prosocial behaviors (Scrimgeour et al., 2015).

Emotion socialization helps children to understand and master the complexities of empathy (Taylor et al., 2013). Children who have parents that positively interact and educate them on emotional development display more empathy and prosocial behaviors (Taylor et al., 2013). The development of empathy is necessary to that of prosocial behavior. Empathy allows children to view other's perspectives and, in turn, helps children behave prosocially (Taylor et al., 2013). Empathy requires an understanding of another's perspective, emotions, and expression (Eisenberg, Fabes, \& Spinrad, 2006). With these skills, children are more prepared and likely to respond in a prosocial way. 
There is a growing body of literature linking emotion socialization and prosocial behavior. For instance, Scrimgeour, Davis, and Buss (2015) found that parents who reported using problem-focused emotion socialization strategies predicted more prosocial behaviors from their children. Mothers using problem-focused emotion socialization strategies were aiding their children in finding a solution to the problems assessed by the Coping with Children's Negative Emotions Scale (Scrimgeour et al., 2015). The results show that parents who reported that they encourage their children to take action and ask questions about the distressing problem presented (i.e. the loss of a toy) displayed more prosocial behaviors over time (Scrimgeour et al., 2015). The parents aiding and guiding children to have a particular response is part of their socialization. Another study, Taylor et al. (2013) followed 18-month-old children for three years to assess the factors that contribute to empathy development, and how empathy was linked to later prosocial development. They found that maternal expression and discussion of personal emotions lead to increased prosocial behavior in children. Moreover, results from a crosssectional study of 2-, 3-, and 5-year-old children indicated that supportive emotion socialization, such as parental emotion coaching, led to increased effortful control which increased prosocial behavior (Miller, Dunsmore, \& Smith, 2015). Furthermore, Garner, Dunsmore, and SouthanGerrow's (2008) reported that maternal explanations of emotions observed at home predicted prosocial behaviors at school in a sample of three and a half to five and a half-year-old children.

These empirical findings support theoretical and conceptual writings on the role of parents in the development of prosocial behavior. For instance, Hasting and colleagues (2007) state that the discussion of emotions and behaviors is crucial to promoting future prosocial behaviors. However, maternal inconsistent socialization practices lead to less prosocial behavior in children (Rosen, 2016); thus, mothers who use inconsistent positive or negative emotion 
socialization strategies will see decreased prosocial behaviors in their children. Without adaptive emotion socialization, we may not see the development prosocial behaviors.

While there are links between emotion socialization and prosocial behavior, most of the studies have focused on general emotion socialization, not the socialization of specific emotions. The current study will focus on the socialization of disappointment and the relation to prosocial behaviors. The socialization of disappointment may help create a better understanding and showing of prosocial behaviors in children. Children may model after their mother's reaction to their own disappointment and use these behaviors in future interactions. Socializing children to disappointment can help them in the real world, not only as a preschooler but in the future as well. Children will be faced with disappointment throughout life. As children learn to work through disappointment they may be more prosocial but they may gain other valuable skills as well like perseverance or compromise. Previous studies have explored the link between parental disappointment and prosocial behaviors. Krevans and Gibbs (1996) suggests that parental disappointment evokes empathy and prosocial behavior from children. Specifically, when parents stated or showed disappointment toward their child's actions, the child may show empathy or increased prosocial behaviors. While supporting the claims of empathy development, Patrick and Gibbs (2007) also suggest that the expression of parental disappointment predicts future child prosocial behavior. However, there is little research focusing on parent's reactions to their child's expression of disappointment. Cole (1984) briefly mentioned that children who sought support from parents when disappointed (i.e. given the wrong toy) were often met with empathic responses and assistance to fix the problem. This study of four to five-year-old preschoolers promotes future research on the socialization of disappointment. Therefore, the first 
aim of the current study was to examine the relations between the socialization of disappointment and the expression of prosocial behavior in a preschool-aged sample.

Emotion socialization and Prosocial behavior: The role of Gender

There are also gender differences in socialization that may affect the development of prosocial behavior in boys and girls. Rosen (2016) confirms that girls and boys display different types of prosocial behaviors. Girls tend to display kindness and consideration, concern, and donating more frequently than boys (Rosen, 2016). Girls are also more likely to display more prosocial behavior than boys at multiple ages (Hastings et al., 2007; Newton et al., 2014). Specifically, using the National Institute of Child Health and Development Study of Early Child Care (NICHD SECC) data set, Newton and colleagues (2014) reported that girls displayed more prosocial behaviors than boys at multiple time points over three years, and they suggested that these gender differences may be due in part to the differences in maternal and paternal parenting. Specifically, girls are more pressured by socialization to behave or display emotions in a specific manor (Chaplin et al., 2005). In some cultures, girls are expected to display only submissive emotions such as sadness and suppress other emotions including anger (Chaplin et al., 2005). These gender differences in socialization may contribute to gender differences in the display of prosocial behavior. Cole and colleagues (1984) state that when faced with disappointment, boys are more likely to express anger while girls, more so than boys, will smile. These reactions to disappointment may be associated with the expression of prosocial behaviors. Girls, who mask or hide disappointment better than boys (Cole et al., 1984), are also more likely to be prosocial (Hastings et al, 2007). Hastings and colleagues (2005) expand on this idea further and stated that girls are more influenced by parental socialization. Moreover, research also suggests that girls are influenced more by maternal expression than their male counterparts (Eisenberg, 1992). 
These gender differences could encourage preschool aged girls to display more prosocial behaviors themselves; indeed, research indicates that women are more prosocial than men (Fieder \& Huber, 2012). Thus, it seems important to include gender in a study of prosocial behavior.

\section{Gender and Prosocial Behavior}

The same parenting may elicit different results from boys and girls (Hastings et al., 2007). Specifically, Hastings, McShane, Parker, \& Ladha (2007) researched maternal and paternal authoritative parenting longitudinally, and reported that maternal and paternal authoritative parenting style predicted more prosocial behaviors. However, these maternal and paternal parenting styles were differentially linked to specific types of prosocial behavior: maternal authoritative parenting predicted more turn taking while paternal predicted more giving (Hastings et al., 2007).

Furthermore, these gender differences are apparent when looking at children. According to Hastings and colleagues (2007), if the same parenting style is being used there will be different outcomes depending on the sex of the child. Girls are more pressured by socialization to behave or display emotions in a specific manor (Chaplin et al., 2005). Girls tend to display more prosocial behaviors than boys do but these differences might not be as evident during the preschool years (Hastings et al., 2007). Previous research suggests that children tend to model more of their behaviors from their same-gender parent (Eisenberg, 1992), and that women in early and middle adulthood tend to be more prosocial than their same age male cohorts (Fieder \& Huber, 2012). Furthermore, mothers tend to play a larger role in the affect that emotion socialization has on prosocial behavior even though the entire family plays a role in behavior development (Scimgeour et al., 2016). Given these associations, the second aim was to examine 
gender as it relates both to the socialization of disappointment and to the expression of prosocial behavior in the current study.

\section{Theoretical Basis}

Sheffield-Morris, Silk, Steinberg, Myers, and Robinson's (2007) Tripartite Model of the Impact of the Family on Children's Emotion Regulation and Adjustment allows for multiple factors to be considered at one time when examining the development of emotional processes. The model was designed to examine the links between observation of parent's reactions to disappointment, parenting practices, emotional climate, emotion regulation, and adjustment (Sheffield-Morris et al., 2007). In the current study, parenting practices, adjustment, and observed parenting behaviors were the focus. The processes described regarding parenting practices are relevant to the current study. This process is considered a family context that deals directly with the socialization of emotions (Sheffield-Morris et al., 2007). Parenting practices and behaviors influence the socialization of the child. Parenting practices, as defined by Sheffield-Morris et al (2007), are more than parenting style and include parent's own interactions with emotions including: reactions to emotions, emotion coaching, and socialization goals. Parental reactions to emotions looks exclusively at how parents' reactions to both positive and negative emotions of their children influence a child's emotion regulation (Sheffield-Morris et al., 2007). This is an important aspect of the theory for the current study. The way parents, especially mothers, respond to children's emotions can influence how the child experiences that emotion later in life. For example, younger children who experience nonsupportive reactions to emotions will have negative expressions of those emotions later (Denham, Wyatt, \& Bassett, 2015). Emotion-coaching, as suggested by Gottman, Katz, and Hooven (1997), follows a pattern where parents observe a child's emotion, teach the child by helping them label the emotion, 
empathize with the child, and help the child problem-solve. Socialization goals are achievements parents want for their children (Sheffield-Morris et al., 2007). These behaviors are observed by children and help expand their emotional intelligence, including behaving in a prosocial way. Indeed, the model applies to the current study because it will focus on both observed parenting during children's disappointment and mothers self-reported emotion socialization to disappointment.

\section{Current Study}

Few studies have looked at the role of the socialization of specific emotions and their connection to prosocial behavior. This study will focus on maternal socialization of disappointment. Most studies that examine the role of disappointment in parenting have focused on parental use, or the expression of disappointment and its relation to discipline (Patrick \& Gibbs, 2007). However, it seems likely that parents' responses to their children's expression of disappointment is an important line of research given its potential relations to the expression of prosocial behavior. Specifically, the expression of disappointment is often connected to social norms which may implore parents to socialize their children to do the most prosocial or socially acceptable behavior when expressing disappointment.

This study will have two different research questions. The first research question will examine positive and negative associations between the socialization of disappointment (maternal report and observed) and prosocial behaviors. It is expected that supportive responses to disappointment (observed and self-reported) will be positively associated with prosocial behavior. Scrimgeour and colleagues (2015) reported that parents who reported using problemfocused emotion socialization strategies also reported higher amounts of prosocial behavior in their children. However, the association between non-supportive emotion socialization responses 
and prosocial behavior will be negative. Denham and colleagues (2015) associated nonsupportive emotion socialization to internalizing and externalizing problems. The findings by Root and Rasmussen (2017) on the socialization of fear suggest that there are differences for socialization of specific emotions.

The second research question will examine the gender differences. First, it is expected that mothers who use supportive socialization will have children who are more prosocial/empathetic. Second, there are expected gender differences in mothers' responses to disappointment. It is hypothesized that mothers will report higher frequency of prosocial behavior in daughters and use more supportive responses with daughters than sons. The rationale behind the research question comes from previous research that suggested that differences in prosocial behavior comes from traits including aggression (Eisenberg \& Fabes, 1998), temperament (Sanson, Hemphill, \& Smart, 2004), and inhibition (Kagan, 1989).

\section{Method}

\section{Participants}

One hundred-three preschool-aged children (55\% boys; $M$ age $=3.73$ years, $S D=.810$ years) and their mothers ( $M$ age $=34.27$ years, $S D=5.039$ years $)$ participated in the larger study. The sample was predominately white (92.2\%), non-Hispanic or Latino (95.3\%), and the majority of mothers $(90.6 \%)$ reported having a college degree or higher. Mothers completed questionnaires and 98 mother-child dyads completed structured laboratory observations. The full sample of this research was not used in this study. Of the 98 who completed the laboratory observations, 65 ( $43 \%$ boys; $M$ age $=3.25$ years, $S D=.935$ years $)$ had data coded at the time of 
analyses for the current study. In addition, there were two children that completed the laboratory session with their father, so they were excluded from the analyses.

Descriptive statistics were run during analysis for the demographics of the sample. The mean age of the children was reported as $3.25(S D=.94)$ with children ranging from two to five years old. The sample included $80.6 \%$ not Hispanic or Latino ethnicity and $2.9 \%$ Hispanic or Latino. Household income was also reported for eighty-six of the children. There were $5.7 \%$ for $\$ 10,000-\$ 25,000,8.7 \%$ for $\$ 25,000-\$ 50,000,11.7 \%$ for $\$ 50,000-\$ 75,000,20.4 \%$ for $\$ 75,000$ $\$ 100,000,22.3 \%$ for $\$ 100,000-\$ 150,000$, and $14.6 \%$ for greater than $\$ 150,000$. For both household income and ethnicity there were seventeen (16.5\%) of the children with missing data.

\section{Procedure}

Participants were recruited using advertisements in the community. Typically-developing children and their mothers were recruited for this study. Mothers, either online or on paper, completed questionnaires prior to visiting the laboratory where structured observations were completed. Laboratory observations, completed by the mother and child together, were approximately thirty-five minutes and included emotion-inducing events. Compensation for this study was given in two ways. Mothers received a \$20.00 gift card and children received $\$ 5.00$ worth of prizes.

\section{Measures - Observation}

Maternal emotion socialization structured observation. Sixty-eight mother-child dyads completed a 35-minute structured observation. The observations were conducted in a structured laboratory at West Virginia University. During the observation, the dyads worked through five tasks: free play, joy induction, frustration induction, fear induction, and disappointment induction. Each task was later coded by a trained research assistant. 
The first task the participants completed was a free play session. During this task, mother and child were allowed to move around the room freely and play with objects as they liked. Then the mother and child went through a series of emotion inductions based on previous research (LAB TAB, e.g., Coan, Davidson, Goldsmith, \& Zugin, 2005; Inhibition Paradigm, e.g., Rubin, Burgess, \& Hastings, 2002): joy (bubble popping task), frustration (toy withdrawal), fear (clown), and disappointment (disappointing gift). The sessions were coded via an interval coding scheme where ratings of at mothers' positive affect/warmth, praise, negative affect, engagement, and intrusiveness/control behavior towards the child were rated (see Appendix A). Each of these maternal observations were examined individually. Each observation was considered to be either supportive or nonsupportive emotion socialization. Supportive observed emotion socialization included positive affect/warmth, praise, and engagement. Nonsupportive observed emotion socialization included negative affect and intrusiveness/control. One trained coder coded the reliability session; the author double coded $20 \%$ of the coding and percent agreement ranged from $67 \%-79 \%$.

This study focused on the disappointment task. At the beginning of the observation, children were asked to rank order five prizes from most favorite to least favorite. At the end of the observation, a researcher would reward the child with the toys he/she chose as being their least favorite. After one minute, the least favorite toy was followed by the most favorite toy.

\section{Measures - Questionnaires}

\section{The coping with children's negative emotions scale (CCNES; Fabes, Eisenberg, \&}

Bernzweig, 1990). Mothers completed a series of questionnaires prior to the observation session, including the Coping with Children's Negative Emotions Scale (CCNES). Two items from CCNES were used to assess the socialization of disappointment. CCNES was completed by 
mothers to assess their responses to their children's emotions. This scale can be found in Appendix B.

Mothers were asked how they reacted to situations involving their children's behaviors and emotions. Each item was rated on a seven-point Likert scale from one "Very Unlikely" to seven "Very Likely." The two items used in this study were "If my child loses some prized possession and reacts with tears, I would:" and "If my child receives an undesirable birth gift from a friend and looks obviously disappointed, even annoyed, after opening it in the presence of the friend, I would:" Mothers rated how likely they would respond in a variety of ways: punishment (e.g., "get upset with him/her for being so careless and then crying about it"); minimization (e.g., "tell my child that he/she is over-reacting"); problem-focused (e.g., "help my child think of places he/she hasn't looked yet"); emotion focused (e.g., "distract my child by talking about happy things"); emotion expressive (e.g., "tell him/her it's OK to cry when you feel unhappy”); and distress (e.g., "feel upset myself.”). Each response was used to calculate the supportive (emotion focused, problem focused) and non-supportive (minimization, punishment, distress) reaction to children's distress (Cronbach's alpha ranged from $\alpha=.46$ to $\alpha=.49$ ).

Pre-school children's behavior questionnaire. Mothers also completed a questionnaire about their children's social skills behaviors. These questionnaires contained items from several different measures, including The Rutter Child Behavior Questionnaires A (Rutter, Tizard, \& Whitmore, 1970); the Social Skills Rating System (Gresham \& Elliott, 1990); and Children's Moods, Fears, \& Worries (Bayer, Sanson, \& Hemphill, 2006). Two items from the pre-school children's questionnaire were used to assess prosocial behaviors in the child participants. Two addition items were reverse coded to assess prosocial behaviors in child participants. These items were used to assess prosocial behaviors in children and create the prosocial/empathetic behavior 
variable used in this study and are stated below. The two items used were 'is kind, loving with other children.' and 'shares toys, belongings with other children.'. The two reverse coded items were 'doesn't share toys.' and 'does not consider the feelings of others.'. Mothers completed this assessment before completing the observation. Mothers were asked to rate how often their child completed each behavior on a six-point Likert scale ranging from one "Almost Never" to five “Almost Always" and six "Don’t Know” ( $\alpha=.76)$.

\section{Data Analysis}

Descriptive statistics were run for all variables of interest. The first research question was addressed via correlation analyses. Both maternal observations and maternal reports were run together. The second research questions were run via independent samples t-tests. Again, observations and reports were run together, and gender was included.

\section{Results}

\section{Hypothesis 1.}

Descriptive statistics were run for all variables. The descriptive statistics for the full sample are found in Table 1. For the first research question, looking at the associations between maternal emotion socialization of disappointment and prosocial behaviors, there was a positive, significant relationship. Maternal observed behavior of negative affect $(M=.07, S D=.40)$ and praise $(M=.02, S D=.07)$ were coded on a two-point scale. On these scales, zero $(0)$ represented no expression and one (1) represented expression. Meaning that for the full sample, mothers showed low negative affect and praise. Maternal observed behavior of engagement $(M=$ $3.54, S D=.49)$, positive affect $(M=1.72, S D=.73)$, and intrusiveness $(M=1.01, S D=.06)$ were coded on a four-point scale. Thus, meaning that mothers displayed high levels of engagement and low to moderate levels of positive affect and intrusiveness during the laboratory 
observation. Maternal reported behavior of responses to children's disappointment were rated on a seven-point scale, with one (1) being very unlikely and seven (7) being very likely. Maternal problem-focused responses $(M=7.32, S D=1.17)$, emotion-focused responses $(M=6.42, S D=$ 2.02), emotion-expressive responses $(M=5.87, S D=1.78)$, and punishment responses $(M=$ $6.19, S D=2.14)$ were high. Meaning that mothers were more likely to respond in these ways to their child's various disappointment. While minimization response $(M=4.23, S D=1.45)$ and distress response $(M=4.35, S D=1.76)$ were moderate. Maternal reports for children's prosocial/empathetic behaviors were rated on a six-point scale where one (1) was almost never and five (5) was almost always and six (6) was don't know. For the full sample, mothers reported prosocial/empathetic behavior with the mean score of $4.52(S D=.58)$. Meaning, in general, that mothers reported that their children were more likely to commit prosocial/empathetic behaviors.

\section{Hypothesis 2.}

Descriptive statistics were also run according to gender, male and female. Descriptive statistics for males can be found in Table 2 and in Table 3 for females. For the second research question, examining maternal supportive socialization and prosocial behaviors, there was a significant relationship. And there were gender differences in mother's responses to disappointment. Maternal observed behavior of negative affect (boys, $M=.05, S D=.31$; girls, $M=.09, S D=.48$ ) and praise (boys, $M=.01, S D=.06$; girls, $M=.02, S D=.09$ ) were low. Positive affect (boys, $M=1.80, S D=.77$; girls, $M=1.64, S D=.69$ ) and intrusiveness (boys, $M$ $=1.00, S D=.03$; girls, $M=1.02, S D=.08)$ were low to moderate. While maternal engagement (boys, $M=3.40$, $S D=.53$; girls, $M=3.71$, $S D=.38$ ) with sons was high. Maternal reported problem-focused response (boys, $M=7.36$, $S D=1.16$; girls, $M=7.28$, $S D=1.19$ ), emotionfocused response (boys, $M=6.58, S D=2.03$; girls, $M=6.22, S D=2.03$ ), emotion-expressive 
response (boys, $M=5.86$, $S D=1.82$; girls, $M=5.89$, $S D=1.76$ ), and punishment response (boys, $M=6.43, S D=1.86$; girls, $M=5.90, S D=2.43$ ) with sons were high. While minimization response (boys, $M=4.39, S D=1.29$; girls, $M=4.04, S D=1.61$ ) and distress response (boys, $M=4.36, S D=1.57$; girls, $M=4.34$, $S D=1.99$ ) were moderate. Mothers reported child's prosocial/empathetic behavior with the mean score of $4.44(S D=.60)$ for boys and the mean score of $4.63(S D=.55)$ for girls. Meaning, for sons and daughters, that mother's reports of prosocial behaviors were high.

Correlations were also run for all variables. Correlation matrix for the full sample can be found in Table 2. After running the analysis, there was a significant, positive relationship between maternal reported child's prosocial/empathic behavior and maternal observed negative affect $(r=.29)$ and maternal reported problem-focused responses $(r=.35)$. Meaning, maternal negative affect during the disappointment task was positively related to prosocial/empathetic behavior in children. Also, mothers who reported using problem-focused responses to children's disappointment was positively related to prosocial/empathetic behaviors. There was a trend finding for maternal report of distress response to child's disappointment; maternal distress was positively associated with prosocial/empathetic behavior $(r=.20)$.

Correlations were run separately by gender and can be found in Table 3. For males, there was a significant, positive relationship between maternal reported prosocial behaviors and maternal reported problem-focused maternal response $(r=.30)$. Meaning mothers who reported using problem-focused responses to the son's disappointment reported higher frequency of prosocial/empathetic behaviors. For females, there was a significant relationship between maternal reported prosocial behaviors and maternal observed negative affect $(r=.44)$ and maternal reported problem-focused response $(r=.44)$. Meaning that mothers who used negative 
affect and reported using problem-focused responses to the daughter's disappointment reported higher frequency of prosocial/empathetic behaviors.

To further examine gender differences, an independent samples t-tests were conducted. Mothers of girls displayed more engagement behaviors during the laboratory observation's disappointment task than mothers of boys $t(59.252)=-2.682, p=.009$.

\section{Discussion}

The purpose of the study was to examine the links between maternal emotion socialization and children's prosocial behaviors. Specifically, the socialization of disappointment was examined for preschooler's prosocial behaviors. The topic was chosen to gain a deeper understanding of the effects of maternal emotion socialization. Denham and colleagues (2015) state that emotion socialization can influence the development of prosocial behavior in children. Similarly, previous research has led to significant findings between maternal emotion socialization and child outcomes like depression (Short et al., 2016), anxiety (Oppenheimer et al., 2016), and prosocial behaviors (Padilla-Walker et al., 2007). However, the current study is unlike many previous research studies because it focused on the socialization of a specific emotion. The emotion of disappointment was chosen to study for several reasons. Cole and colleagues (1994) focused greatly on children's expression of disappointment and their reaction to a disappointing task. They observed that children had a difficult time hiding or masking this emotion. However, children tended to handle disappointment in a better way when surrounded by a familiar adult or their mother (Cole, 1984; Cole et al., 1994. These findings show that mothers have a great influence on the socialization of disappointment and have the opportunity to teach children how to handle and problem-solve disappointing situations.

\section{Contributions}


The findings in this study confirmed the proposed research questions. The first research question stated that supportive responses (both observed and reported) to disappointment were expected to be positively associated with prosocial behaviors. The second research question focused on gender differences and was broken down into two sub questions. First, it was expected that maternal supportive socialization would predict increased prosocial behavior. Second, it was predicted that there would be gender differences in maternal responses to disappointment. There were specific observed and reported maternal behaviors that were linked to prosocial/empathetic behaviors. There was also evidence of child's gender differences in the maternal reported prosocial/empathetic behaviors and maternal observed engagement. However, not all of the maternal behaviors, reported and observed, were associated with prosocial/empathic behavior.

The first research question, stating that maternal supportive responses to disappointment would predict prosocial behavior, was supported in the findings. Observed maternal negative affect positively influenced children's prosocial behavior/empathy. Maternal reported problemfocused responses to child's disappointment also positively influenced prosocial behavior/empathy. The relation between maternal observed engagement and reported distressfocused responses both approached significance in their relation to prosocial behavior/empathy.

There are a few explanations for these findings. When a mother uses negative affect when a child is faced with disappointment we may see more prosocial behaviors because children are viewing the negative affect from the mother as a response to their misbehaving. Children, especially during these years, may express disappointment by crying or yelling (Cole, Zhan-Waxler, \& Smith, 1994; Ekman \& Friesen, 1978), acts that have previously been deemed as misbehaving. So, when their mothers scold them or display anger, children may associate that 
maternal behavior with punishment to their response to the disappointment. Children want to maintain high-quality mother-child relationships and may use negative responses as learning opportunities (Pastorelli et al., 2016). When a mother responds to disappointment by using negative affect the child may feel as though the quality of the mother-child relationship is being threatened. Therefore, the child may later remember this uncertainty and behave in a prosocial or empathetic manner to peers, friends, or others (Davidov \& Grusec, 2006).

It also may be that maternal responses help children perspective take. Children may remember these negative responses when they are placed in situations where prosocial behaviors are appropriate. Premo and Kiel (2015) found that parents socialize their children through their own emotional reactions. Children may then use their memory of their mother's reactions and responsiveness to remember how they felt and respond to others in a more prosocial way (Davidov \& Grusec, 2006). Maternal responses to disappointments link to prosocial behavior may be supported by children's empathy as well. Children learn to be empathetic through sensitive parenting (Denham, Bassett, \& Wyatt, 2015). Empathy is supported by emotion socialization and can help children with this perspective taking (Taylor et al., 2013). Children learn to read other children's emotions and apply empathy and prosocial behavior through past parental interactions (Fabes, Poulin, Eisenberg, \& Madden-Dierdich, 2002).

To further explain the finding that maternal supportive responses to disappointment are predictive of prosocial behaviors we examine maternal report of using problem-focused responses to disappointment, a supportive response. This type of response is founded in tolerance, encouragement, and validation (Scimegour et al., 2015). Children may later model after their parent's responses to their own disappointment with peers, friends, and other individuals. Children may use similar tactics as their parents to help those they see experiencing 
distress. Other types of supportive responses have been linked to prosocial behaviors in children (Scimegour et al., 2015). Specifically, children may use problem-focused responses to disappointment to help settle others.

The analysis indicated that the relation between maternal reported distress-focused responses and children's prosocial behavior/empathy approached significance. This finding is likely similar to the findings linking observed negative affect to prosocial behavior/empathy. These types of responses may elicit perspective taking from children and encourage them to use prosocial/empathetic behaviors in later situations. The relation between maternal observed engagement and prosocial behavior/empathy also approached significance. Padilla-Walker and colleagues (2012) stated that engagement in the home and with the family promotes prosocial behaviors in children. The reason we may not have seen significance here but rather an approach to significance was due to the nature of the studied. As done in the Padilla-Walker et al (2012) study we may only see this significance in the natural setting of the mother-child dyad. In the home setting, mothers and other family members may have different engagement levels or strategies that were not seen in the study.

There are many studies that have examined the link between gender and prosocial behavior (Hastings et al., 2007; Newton et al., 2014). Typically, girls will express or exhibit more prosocial behaviors than boys (Newton et al., 2014). Furthermore, girls and boys express prosocial behaviors differently. Girls more frequently express compassion, helpfulness and sympathy and boy's express friendliness and engagement (Hastings et al., 2007). Boys prosocial behaviors tend to be more active (Hastings, Utendale, \& Sullivan, 2007) and assertive (Hastings et al., 2007), which often go unnoticed. It is also observed that as children age their types and complexities of prosocial behaviors change (Hastings et al., 2007). As children age, they start to 
move away from prosocial behaviors like social inclusion and sharing and towards more complex behaviors like empathy and altruism (Hastings et al., 2007). Both age and gender may be influencers in the display of prosocial behaviors.

The current study found that maternal observed negative affect during a child's disappointment was significantly related to prosocial/empathetic behavior for girls but not boys. Girls may be more affected or influenced by these expressions of negative affect. This may be explained by Eisenberg's (1992) findings that daughters, more so than sons, are more influenced by their mother's expressions during interactions. Same-sex parent-child dyads have more influence on one another's emotional expression and reactivity (Fabes, Eisenberg, \& Miller, 1990). Meaning, that mothers are more likely to influence their daughters while fathers are more likely to influence their sons.

Finally, the findings indicated that mothers of girls displayed more observed engagement during the disappointment task than mothers of boys. There may be many different influencing factors on the role of maternal engagement with daughters versus sons. Cole and colleagues (1994) found that boys have a harder time dealing with disappointment. These gender differences may encourage mothers to be more engaged with children who are having a less difficult time coping with their present disappointment. Mother's may respond to boy's disappointment in a less meaningful way, or they may not take their disappointment as seriously as girls.

Moreover, the fact that the study was done exclusively with mothers and children may also be an influence. According to Hastings (2015), parents are primarily responsible for socializing their same gender children, which adds support to the findings that mothers were more engaged with daughters than sons. This varying level of engagement may also influence the frequency of prosocial behavior in boys versus girls. Day and Padilla-Walker (2009) found 
that mother's involvement, which included engagement, was linked to prosocial behaviors. As previously mentioned, not all of the data that was analyzed had significant findings. However, that does not mean they are not important. In maternal observed behaviors, there was no significance between positive affect, praise, or intrusiveness and prosocial/empathetic behavior. Maternal reports of emotion-focused responses, emotion-expressive responses, punishment responses, and minimization responses to child's disappointment also reported no significant relationship to prosocial/empathetic behaviors. Emotion-focused and emotionexpressive responses may not allow the children to gain empathetic skills. These types of responses may allow the child to focus on their disappointment rather than a solution. Having children focus on their emotion (i.e. disappointment) does not allow them to look for a solution. It may allow children to become more skillful at expressing and recognizing the emotion (Denham, Bassett, \& Wyatt, 2015) but it may not provide a solution to overcome the emotion. Punishment responses may have a similar effect. They may force the child to focus on their wrong doing rather than a solution to the problem. Finally, minimization responses may not socialize children to show compassion or empathy to those in similar situations due to the nature of the response. The response given by the mother minimizes the child's emotion. This may not allow the child to fully express or understand the emotion, not allowing them to empathize with others in a similar situation.

Finally, there were many behaviors that did not have any specific gender differences. Mothers were observed and reported behaving similarly with both boys and girls. There were no significant differences in maternal observed negative affect, positive affect, praise or intrusiveness. Also, there were no gender differences in reported problem-focused responses, emotion-focused responses, emotion-expressive responses, punishment responses, minimization 
responses, or distress responses. There may not have been any gender differences here due to the studied emotion, disappointment. It may be interesting and important to look at these observed and reported behaviors in terms of other emotions like fear or anger. However, because disappointment was studied, there may not have been the opportunity for such gender differences. It may be important to investigate emotions where there are already noted gender differences. For example, Chaplin and Aldao (2013) found that even in the preschool years boys were more likely than girls to express anger; moreover, Brody and Hall (2008) stated that girls more so than boys were likely to express fear. Thus, it may be that boys and girls express disappointment in similar ways.

\section{Limitations}

The study was not without its limitations. Although specifically looking at mothers, there was little diversity in maternal race/ethnicity and household income. To improve on this study, it would be necessary to include more racial/ethnic diversity as well as households that would be considered low socioeconomic status (SES). Previous research has shown that minority and lower SES families have increased stress (Cohen \& Janicki-Deverts, 2012), and limited access to community resources (Estabrooks, Lee, \& Gyurcsik, 2016) and educational (parenting) training (McLeod \& Kessle, 1990). Due to these differences, as well as differences in parenting styles and stress levels, we may expect different emotion socialization from minority or lower SES mothers. For instance, McKee and colleagues (2015) found that single African American mothers were more likely to respond to their adolescent's positive affect with expansion or praise. The findings were different than what was expected based on the sample's ethnicity. McKee and colleagues (2015) stated that mothers focused on an entire interaction of positive affect, not just individual segments, which may be linked to the ethnicity of the sample. These 
mothers may respond to disappointment in different ways than the sample that was studied due to past experience or economic stress thus socializing their children to do the same. Mothers who come from a more diverse background may experience disappointment more often in their daily lives, seeing it as a normal part of life. This may make them socialize disappointment to their child in a different way; they may use responses such as minimization more frequently than the studied sample.

Due to our knowledge about differences among regions and cultures these findings should not be generalized and should only be considered for populations similar to the sample. Another limitation of the study was the data collection method for prosocial behaviors. Mothers may have reported inaccurate levels of prosocial behaviors for their children. In future studies, if possible, researchers should use a naturalistic observation method to collect data on children's prosocial behaviors. Children may need to be observed in their home or school setting interacting with others. The final limitation of this study was the structured laboratory task for disappointment. To fully understand how a mother will socialize disappointment it may be necessary to view this interaction in many settings. Halberstadt and Eaton (2002) believed that most emotion socialization, especially during the early years, happens in a home setting. Cole and colleagues (1994) observed that children masked emotion better when a familiar adult was present.

\section{Future Directions}

The findings produced by this study open the field for future directions. As mentioned previously, one of the biggest gaps in the current socialization literature is the focus on socialization of specific emotions and their influence on outcomes. Previous research has started to fill this gap by looking at emotions such as fear and anger. Kiel has extensive research focused 
on socialization of sadness, anger, and fear in toddlers. While Root and Rasmussen (2017) found that mothers of children who they reported as having low inhibition were more supportive of their child's fear emotion. The findings that maternal socialization of disappointment is associated with prosocial behaviors is a great contribution to continue to look at socialization of other specific emotions.

The finding that mothers are more engaged with their daughters than sons may also influence future works in the field. There are previous works that state same-sex parent-child dyads (i.e. mother-daughter, father-son) tend to have more influence on one another (Fabes, Eisenberg, \& Miller, 1990). The mother-daughter engagement findings of the current study connected the links between socialization of specific emotions and same-sex parenting. This the opportunity to look at paternal emotion socialization and gender differences.

Other future directions for this study may be to include other variables of importance. Sanson, Hemphill, and Smart (2004) found an association between temperament and prosocial behavior in a review of many studies. Root and Rasmussen (2017) found that preschool children who had low inhibition had mothers who responded to fear in a nonsupportive way. Furthermore, other family characteristics like marital conflict (Wong, McElwain, \& Halberstadt, 2009), maternal depression (Premo \& Kiel, 2016), and socioeconomic status (Garner, Jones, \& Miner, 1994) have all been associated with emotion socialization. Including other variables like inhibition, temperament, and family characteristics in the socialization of disappointment may be beneficial to the field. All of the previously mentioned variables, and others, relate to disappointment because they influence how a child might experience or express disappointment. Depending on each of the previously stated variables and their relationships with one another, the children may experience and express disappointment in a unique way. These past findings, 
plus the findings of the current study opens the door for more exploration into the topic of emotion socialization and prosocial development.

Although these findings are useful for the field of human development, they also have practical applications. Having the knowledge that certain maternal responses during disappointment can lead to prosociality can be adapted for the real world. These findings can be used to create interventions, trainings, or skills for mothers to use to promote prosocial/empathetic behaviors in their children. One practical example may be through maternal response training ingrained in programs like Head Start or Birth to Three. These trainings could teach mothers to respond to their children's disappointment using problem-focused responses. Through the programs the mothers could learn what problem-focused responses look and sound like and practice using them. 


\section{References}

Altay, F. B. \& Gure, A. (2012). Relationship among the parenting styles and the social competence and prosocial behaviors of the children who are attending to state private preschools. Educational Sciences: Theory \& Practice, 12, 2712-2718.

Baumrind, D. (1966). Effects of authoritative parental control on child behavior, Child Development, 37, 887-907.

Bowlby, J. (1973). Attachment and loss: Vol. 2: Separation: Anxiety and anger, London, UK: Hogarth Press.

Breaux, R. P., Harvey, E. A., \& Lugo-Candelas, C. L. (2016). The role of parent psychopathology in emotion socialization. Journal of Abnormal Child Psychology, 44, 731-743.

Brody, L. R., \& Hall, J. A. (2008). Gender and emotion in context. In M. Lewis, J. M. HavilandJones, \& L. F. Barrett (Eds.), Handbook of emotions ( $3^{\text {rd }}$ ed., pp. 395-408). New York, NY: Guilford Press.

Cassidy, J. (1994). Emotion regulation: Influences of attachment relationships. In N. A. Fox (Ed.), the development of emotion regulation: Biological and behavioral considerations. Monographs of the society for Research in Child Development, 59, 228-249.

Chaplin, T. M., Cole, P. M., \& Zahn-Waxler, C. (2005). Parental socialization of emotion expression: Gender differences and relations to child adjustment. Emotion, 5, 80-88.

Chaplin, T. M., \& Aldao, A. (2013). Gender differences in emotion expression in children: A meta-analytic review, Psychological Bulletin, 139, 735-765. 
Choukas-Bradley, S., Giletta, M., Cohen, G. L., \& Prinstein, M. J. (2015). Peer influence, peer status, and prosocial behavior: An experimental investigation of peer socialization of adolescents' intentions to volunteer. Journal of You Adolescence, 44, 2197-2210.

Cohen, S. \& Janicki-Deverts, D. (2012). Who's stressed? Distributions of psychological stress in the United States in probability samples from 1983, 2006, and 2009. Journal of Applied Social Psychology, 42, 1320-1334.

Cole, P. M. (1984). Children's spontaneous control of facial expression. Child Development, 57, 1309-1321.

Cole, P. M., Zahn-Waxler, C., \& Smith, K. D. (1994). Expressive control during a disappointment: Variations related to preschoolers' behavior problems. Developmental Psychology, 30, 835-846.

Crandall, A., Ghazarian, S. R., Day, R. D., \& Riley, A. W. (2016). Maternal emotion regulation and adolescent behaviors: The mediating role of family functioning and parenting. Journal of Youth Adolescence, 45, 2321-2235.

Davidov, M, \& Grusec, J. E. (2006). Untangling the links of parental responsiveness to distress and warmth to child outcomes. Child Development, 77, 44-58.

Day, R. D. \& Padilla-Walker, L. M. (2009). Mother and father connectedness and involvement during early adolescence. Journal of Family Psychology, 23, 900-904.

Denham, S. A., Bassett, H. H., \& Wyatt, T. (2015). The socialization of emotional competence. In J. Grusec \& P. Hastings (Eds.), The Handbook of Socialization: Theory and Research (pp. 590-613). New York: Guilford Press.

Dunn, J., Deater-Deckard, K., Pickering, K., O’Connor, T. G., Golding, J., \& ALSPAC Study Team. (1998). Children's adjustment and prosocial behavior in step-, single-parent, and 
non-stepfamily settings: Findings from a community study. Journal of Child Psychology and Psychiatry, 39, 1083-1095.

Eisenberg, N. (1992). The caring child. Journal of Community and Applied Social Psychology, 4, 372-373.

Estabrooks, P. A., Lee, R. E., \& Gyurcsik, N. C. (2016). Resources for physical activity participations: Does availability and accessibility differ by neighborhood socioeconomic status? Annals of Behavioral Medicine, 25, 100-104.

Eisenberg, N. \& Fabes, R. A. (1998). Prosocial development. In W. Damon (Series Ed.) \& N. Eisenberg (Vol. Ed.), Handbook of child psychology: Vol. 3. Social, emotional and personality development ( $5^{\text {th }}$ ed.). New York: Wiley.

Eisenberg, N., Fabes, R. A., \& Spinrad, T. L. (2006). Prosocial development. In N. Eisenberg, W. Damon, \& R. M. Lerner (Eds.), Handbook of child psychology: Vol. 3, Social, emotional, and personality development (6th ed., pp. 646-718). Hoboken, NJ: Wile

Fabes. R. A., Eisenberg, N., \& Miller, P A. (1990), Maternal correlates of children's vicarious emotional responsiveness. Developmental Psychology, 26, 639-648.

Fabes, R. A., Poulin, R. E., Eisenberg, N., \& Madden-Derdich, D. A. (2002). The Coping with Children's Negative Emotions Scale (CCNES): Psychometric properties and relations with children's emotional competence. Marriage and Family review, 34, 285-310.

Fieder, M. \& Huber, S. (2012). The association between pro-social attitude and reproductive success differs between men and women. Plosone, 7.

Flynn, E., Ehrenreich, S. E., Beron, K. J., \& Underwood, M. K. (2015). Prosocial behavior: Long-term trajectories and psychosocial outcomes. Social Development, 24, 462-482. 
Garner, P. W., Dunsmore, J. C., \& Southam-Gerrow, M. (2008). Mother-child conversations about emotions: Linkages to child aggression and prosocial behavior. Social Development, 17, 259-277.

Garner, P. W., Jones, D. C., \& Miner, J. L. (1994). Social competence among low-income preschoolers: Emotion socialization practices and social cognitive correlates. Child Development, 65, 622-637.

Gottman, J. M., Katz, L. F., \& Hooven, C. (1997). Meta-emotion. Mahwah, NJ: Lawrence Erlbaum.

Gunnar, M. R. (2000). Early adversity and the development of stress reactivity and regulation. In C. A. Nelson (Ed.), Minnesota Symposia on Child's Psychology: Vol. 31. The effects of early adversity on neurobehavioral development (pp. 163-200). Mahwah, NJ: Erlbaum.

Halberstadt, A. G., \& Eaton, K. L. (2002). A meta-analysis of family expressiveness and children's emotional expressiveness and understanding. Marriage \& Family Review, 34, $35-62$.

Hastings, P. D., McShane, K. E., Parker, R., \& Ladha, F. (2007). Ready to make nice: Parental socialization of young sons' and daughters' prosocial behaviors with peers. The Journal of Genetic Psychology, 168, 177-200.

Hastings, P. D., Rubin, K. H., \& DeRose, L. (2005). Links among gender, inhibition, and parental socialization in the development of prosocial behavior, Merrill-Palmer Quarterly, 51, 467-493.

Hastings, P. D., Utendale, W. T., \& Sullivan, C. (2007). The socialization of prosocial development. In J. E. Grusec \& P. D. Hastings (Eds.), Handbook of socialization (pp. 638-664). New York: Guilford Press. 
Kagan, J. (1989). The concept of behavioral inhibition to the unfamiliar. In J. S. Reznick (Ed.), Perspectives on behavioral inhibition (pp. 1-23). Chicago: University of Chicago Press.

Krevans, J. \& Gibbs, J. C. (1996). Parents' use of inductive discipline: Relations to children's empathy and prosocial behavior. Child Development, 67, 3263-3277.

Laible, D. J., Carlo, G., \& Roesch, S. C. (2004). Pathways to self-esteem in late adolescence: The role of parent and peer attachment, empathy, and social behaviors. Journal of Adolescence, 27, 703-716.

London Bocknek, E., Brophy-Herb, H. E., \& Banerjee, M. (2009). Effects of parental supportiveness on toddlers' emotion regulation over the first three years of life in lowincome African American sample. Infant Mental Health Journal, 30, 452-476.

McKee, L.G., Faro, A. L., O’Leary, J. L., Spratt, K. H., \& Jones, D. J. 2015. Socializing positive emotion: A qualitative study of African American single mothers and their adolescent youth. Interdisciplinary Journal of Applied Family Studies, 64, 635-650.

McLeod, J.D. \& Kessler, R. C. (1990). Socioeconomic status differences in vulnerability to undesirable life events. Journal of Health and Social Behavior, 31, 162-172.

Miller, R. L., Dunsmore, J. C., \& Smith, C. L. (2015). Effortful control and parents' emotion socialization patterns predict children's positive social behavior: A person-centered approach. Early Education and Development, 26, 167-188.

Newland, R. P. \& Crnic, K. A. (2011). Mother-child affect and emotion socialization processes across the late preschool period: Predictions of emerging behavior problems. Infant and Child Development, 20, 371-388. 
Newton, E. K., Laible, D., Carlo, G., Steele, J. S., \& McGinley, M. (2014). Do sensitive parents foster kind children, or vice versa? Bidirectional influences between children's prosocial behavior and parental sensitivity. Developmental Psychology, 50, 1808-1816.

Oppenheimer, C. W., Ladouceur, C. D., Waller, J. M., Ryan, N. D., Benoit Allen, K., Sheeber, L., Forbes, E. E., Dahl, R. E., \& Silk, J. S. (2016). Emotion socialization in anxious youth: Parenting buffers emotional reactivity to peer negative events. Journal of Abnormal Child Psychology, 44, 1267-1278.

Padilla-Walker, L. M., Carlo, G., Christensen, K. J., \& Yorgason, J. B. (2012). Bidirectional relations between authoritative parenting and adolescents' prosocial behaviors. Journal of Research on Adolescence, 22, 400-408.

Pastorelli, C., Landsford, J. E., Kanacri, B. P. L., Malone, P. S., Di Giunta, L., Bacchini, D., Bombi, A. S., ... Sorbring, E. (2016). Positive parenting and children's prosocial behavior in eight countries. Journal of Child Psychology, 57, 824-834.

Patrick, R. B. \& Gibbs, J. C. (2007). Parental expression of disappointment: Should it be a factor in Hoffman's model of parental discipline? The Journal of Genetic Psychology, 168, 131145.

Premo, J. E. \& Kiel, E. J. (2016). Maternal depressive symptoms, toddler emotion regulation, and subsequent emotion socialization. Journal of Family Psychology, 30, 276-285.

Rodgers, M. L., Halberstadt, A. G., Castro, V. L., MacCormack, J. K., \& Garrett-Peters, P. (2016). Maternal emotion socialization differentially predicts third-grade children's emotion regulation and lability. Emotion, 16, 280-291. 
Root, A. E. \& Rasmussen K. E. (2017). Maternal emotion socialization: The contribution of inhibited behavior and mothers' dissatisfaction with the parent-child relationship. Infant and Child Development, 26.

Rosen, K. S. (2016). Social and emotional development: Attachments relationships and the emerging self. London, United Kingdom: Palgrave.

Sanson, A., Hemphill, S. A., \& Smart, D. Connections between temperament and social development: A review. Oxford, United Kingdom: Blackwell Publishing.

Scrimgeour, M. B., Davis, E. L., \& Buss, K. A. (2016). You get what you get and you don't throw a fit!: Emotion socialization and child physiology jointly predict early prosocial development. Developmental Psychology, 52, 102-116.

Scrimgeour, M. B., Blandon, A. Y., Stifter, C. A., \& Buss, K. A. (2013). Cooperative coparenting moderates the association between parenting practices and children's prosocial behavior. Journal of Family Psychology, 27, 506-511.

Shortt, J. W., Katz, L. F., Allen, N. B., Leve, C., Davis, B., \& Sheeber, L. B. (2016). Emotion socialization in the context of risk and psychopathology: Mother and after socialization of anger and sadness in adolescents with depressive disorder. Social Development, 25, 2746.

Sheffield Morris, A., Silk, J. S., Steinberg, L., Myers, S. S., \& Robinson, L. R. (2007). The role of the family context in the development of emotion regulation. Social Development, 16, 361- 388 .

Taylor, Z. E., Eisenberg, N., Spinard, T. L., Eggum, N. D., \& Sulik, M. J. (2013). The relations of ego-resiliency and emotion socialization to the development of empathy and prosocial behavior across early childhood. Emotion, 13, 822-831. 
Van der Pol, L. D., Groeneveld, M. G., Endendijk, J. J., van Berkel, S. R., Hallers-Haalboom, E. T., Bakermans-Kranenburg, M. J., \& Mesman, J. (2016). Associations between fathers' and mothers' psychopathology symptoms, parental emotion socialization, and preschoolers' social-emotional development. Journal of Child and Family Studies, 25, 3367-3380.

Wong, M. S., McElwain, N. L., \& Haberstadt, A. G. (2009). Parent, family, and child characteristics: Associations with mother- and father-reported emotion socialization practices. Journal of Family Psychology, 23, 452-463. 
Table 1.1

Descriptive Statistics of Negative Affect, Positive Affect, Engagement, Praise, Intrusiveness, Problem-focused Response, Emotion-focused Response, Emotion-expressive Response, Punishment Response, Minimization Response, Distress response, and Prosocial and Empathy

\begin{tabular}{llll}
\hline Variables & M & SD & Range \\
\hline 1. Negative Affect & .07 & .40 & $.00-2.63$ \\
2. Positive Affect & 1.72 & .73 & $.00-3.50$ \\
3. Engagement & 3.54 & .49 & $2.20-4.43$ \\
4. Praise & .02 & .07 & $.00-.44$ \\
5. Intrusiveness & 1.01 & .06 & $1.00-1.43$ \\
6. Problem-focused & 7.32 & 1.17 & $4.50-10.50$ \\
7. Emotion-focused & 6.42 & 2.02 & $2.50-10.50$ \\
8. Emotion- & 5.87 & 1.78 & $1.50-10.50$ \\
expressive & & & \\
9. Punishment & 6.19 & 2.14 & $2.00-10.50$ \\
10. Minimization & 4.23 & 1.45 & $2.00-8.50$ \\
11. Distress & 4.35 & 1.76 & $1.50-10.50$ \\
12. Prosocial and & 4.52 & .58 & $3.25-5.75$ \\
Empathy & & & \\
\hline
\end{tabular}


Table 1.2

Descriptive Statistics of Negative Affect, Positive Affect, Engagement, Praise, Intrusiveness, Problem-focused Response, Emotion-focused Response, Emotion-expressive Response, Punishment Response, Minimization Response, Distress response, and Prosocial and Empathy for Males and Females

\begin{tabular}{|c|c|c|c|c|c|c|}
\hline \multirow{2}{*}{$\begin{array}{l}\text { Gender } \\
\text { Variables } \\
\end{array}$} & \multicolumn{3}{|c|}{ Male } & \multicolumn{3}{|c|}{ Female } \\
\hline & $\mathrm{M}$ & SD & Range & $\mathrm{M}$ & SD & Range \\
\hline 1. Negative Affect & .05 & .31 & $.00-1.83$ & .09 & .48 & $.00-2.63$ \\
\hline 2. Positive Affect & 1.80 & .77 & $.00-3.50$ & 1.64 & .69 & $.00-3.29$ \\
\hline 3. Engagement & 3.40 & .53 & $2.20-4.00$ & 3.71 & .38 & $2.67-4.43$ \\
\hline 4. Praise & .01 & .06 & $.00-.33$ & .02 & .09 & $.00-.44$ \\
\hline 5. Intrusiveness & 1.00 & .03 & $1.00-1.17$ & 1.02 & .08 & $1.00-1.43$ \\
\hline 6. Problem-focused & 7.36 & 1.16 & $\begin{array}{l}5.50- \\
10.50\end{array}$ & 7.28 & 1.19 & $\begin{array}{l}4.50- \\
10.00\end{array}$ \\
\hline 7. Emotion-focused & 6.58 & 2.03 & $\begin{array}{l}2.50- \\
10.50\end{array}$ & 6.22 & 2.03 & $\begin{array}{l}2.50- \\
10.50\end{array}$ \\
\hline $\begin{array}{l}\text { 8. Emotion- } \\
\text { expressive }\end{array}$ & 5.86 & 1.82 & $\begin{array}{l}3.50- \\
10.50\end{array}$ & 5.89 & 1.76 & $1.50-8.00$ \\
\hline 9. Punishment & 6.43 & 1.86 & $\begin{array}{l}2.50- \\
10.50\end{array}$ & 5.90 & 2.43 & $\begin{array}{l}2.00- \\
10.50\end{array}$ \\
\hline 10. Minimization & 4.39 & 1.29 & $2.00-8.50$ & 4.04 & 1.61 & $2.00-8.50$ \\
\hline 11. Distress & 4.36 & 1.57 & $1.50-9.50$ & 4.34 & 1.99 & $\begin{array}{l}1.50- \\
10.50\end{array}$ \\
\hline $\begin{array}{l}\text { 12. Prosocial and } \\
\text { Empathy }\end{array}$ & 4.44 & .60 & $3.25-5.50$ & 4.63 & .55 & $3.25-5.75$ \\
\hline
\end{tabular}


Table 2

Full Sample Correlations for all Measures

\begin{tabular}{|c|c|c|c|c|c|c|c|c|c|c|c|c|}
\hline & 1. & 2. & 3. & 4. & 5. & 6. & 7. & 8. & 9. & 10. & 11. & 12. \\
\hline 1. Negative & - & - & .17 & - & - & .17 & -.01 & -.02 & -.14 & -.10 & .25 & $.29 *$ \\
\hline Affect & & $.42 * *$ & & .04 & .04 & & & & & & & \\
\hline 2. Positive & & - & - & .15 & .06 & .08 & .11 & .05 & -.09 & -.06 & -.09 & .13 \\
\hline Affect & & & .01 & & & & & & & & & \\
\hline 3. & & & - & - & .02 & .26 & .26 & .16 & .07 & .15 & -.17 & .21 \\
\hline Engagement & & & & .01 & & & & & & & & \\
\hline 4. Praise & & & & - & $\begin{array}{l}- \\
.05\end{array}$ & .00 & .09 & -.05 & -.17 & -.08 & .09 & -.11 \\
\hline 5. & & & & & - & - & -.25 & .02 & -.07 & $-.29 *$ & -.13 & .01 \\
\hline Intrusiveness & & & & & & .01 & & & & & & \\
\hline $\begin{array}{l}\text { 6. Problem- } \\
\text { focused }\end{array}$ & & & & & & - & $.30 * *$ & $.36 * *$ & -.14 & -.00 & -.07 & $.35 * *$ \\
\hline $\begin{array}{l}\text { 7. Emotion- } \\
\text { focused }\end{array}$ & & & & & & & - & .14 & $-26^{*}$ & $.32 * *$ & $-30 * *$ & .114 \\
\hline $\begin{array}{l}\text { 8. Emotion- } \\
\text { expressive }\end{array}$ & & & & & & & & - & -.14 & -.01 & -.14 & .15 \\
\hline 9. & & & & & & & & & - & .07 & $.44 * *$ & -.10 \\
\hline Punishment & & & & & & & & & & & & \\
\hline 10. & & & & & & & & & & - & $.29 *$ & -.04 \\
\hline Minimization & & & & & & & & & & & & \\
\hline 11. Distress & & & & & & & & & & & - & .20 \\
\hline $\begin{array}{l}\text { 12. Prosocial } \\
\text { and Empathy }\end{array}$ & & & & & & & & & & & & - \\
\hline
\end{tabular}

Note. $* p<.05$, two tailed; $* * p<.01$, two-tailed 
Table 3

Correlation for Male and Female

\begin{tabular}{|c|c|c|c|c|c|c|c|c|c|c|c|c|}
\hline & 1. & 2. & 3. & 4. & 5. & 6. & 7. & 8. & 9. & 10. & 11. & 12. \\
\hline $\begin{array}{l}\text { 1. Negative } \\
\text { Affect }\end{array}$ & - & $-41 *$ & .20 & -.04 & -.03 & .04 & -.02 & .13 & -.20 & -.05 & -.07 & .07 \\
\hline $\begin{array}{l}\text { 2. Positive } \\
\text { Affect }\end{array}$ & $-.45^{*}$ & - & -.02 & .23 & $.39 *$ & -.17 & -.08 & -.17 & .08 & -.23 & .07 & .09 \\
\hline $\begin{array}{l}3 . \\
\text { Engagement }\end{array}$ & .15 & .12 & - & -.21 & .03 & .33 & .33 & .15 & .21 & .28 & -.24 & .19 \\
\hline 4. Praise & -.05 & .11 & .15 & - & -.04 & -.27 & .04 & -.20 & -.14 & -.13 & .08 & -.33 \\
\hline $\begin{array}{l}5 . \\
\text { Intrusiveness }\end{array}$ & -.05 & -.04 & - & -.07 & - & -.20 & -.12 & -.19 & .01 & -.14 & .11 & .07 \\
\hline $\begin{array}{l}\text { 6. Problem- } \\
\text { focused }\end{array}$ & .25 & $.39 *$ & .19 & $.41 *$ & .04 & - & .26 & $.39 *$ & .05 & .11 & -.19 & $.30 *$ \\
\hline $\begin{array}{l}\text { 7. Emotion- } \\
\text { focused }\end{array}$ & .01 & .31 & .25 & .15 & -.33 & $.35^{*}$ & - & .16 & -.06 & $.33^{*}$ & $-.38 *$ & .04 \\
\hline $\begin{array}{l}\text { 8. Emotion- } \\
\text { expressive }\end{array}$ & -.14 & .35 & .21 & .22 & .12 & .32 & .11 & - & $-.33^{*}$ & .08 & -.08 & .21 \\
\hline $\begin{array}{l}9 . \\
\text { Punishment }\end{array}$ & -.10 & -.30 & .04 & -.27 & -.07 & -.32 & $.47 * *$ & .05 & - & .02 & $.41 * *$ & .06 \\
\hline $\begin{array}{l}10 . \\
\text { Minimization }\end{array}$ & -.12 & .05 & .16 & -.05 & -.32 & -.11 & .30 & -.10 & .08 & - & .15 & -.18 \\
\hline 11. Distress & $.53 * *$ & -.35 & .07 & .07 & -.20 & .04 & -.24 & -.20 & $.46^{* *}$ & $.39 *$ & - & .12 \\
\hline $\begin{array}{l}\text { 12. Prosocial } \\
\text { and Empathy }\end{array}$ & $.44^{*}$ & .21 & .23 & .24 & -.03 & $.44^{*}$ & .26 & .06 & -.23 & .19 & .31 & - \\
\hline
\end{tabular}

Note. $* p<.05$, two tailed; $* * p<.01$, two-tailed; Female on bottom, Male on top 


\section{Appendix A \\ OBSERVATIONAL CODING: MOTHER \\ Modified by A.E.R. 10/1/15}

\section{Positive Affect/Warmth}

This is a measure of positive affect/emotion towards the child. It does not necessarily measure the presence of negative affect (i.e., you can be low in positive and not express negative affect)

1. No evidence of positive emotion/warmth

2. Low intensity positive--slight/very brief smile; uses a very slight po9sitive tone or uses a positive tone very briefly

3. Moderate positive --clear smile or prolonged slight smiles; uses more prolonged positive tone; mother may touch child affectionately (e.g., touches arm gently; rubs back - this should NOT be confused with praise (i.e., high five or fist bump)).

4. Intense positive--intense smile or laugh, or smiling for more prolonged period; uses a very positive tone or uses a positive tone for the majority of the time; mother may give a hug or be physically affectionate with the child.

\section{Praise (of task action or child)}

Praising or encouraging the child's actions or result of child's actions; ("Good job!" "You're doing it!" "Yea!" "You can do it!"); may also include clapping in approval.

Praising the child directly on a global level; ("You're so smart!" "Good girl!" "You're so good at this!").

0. No

1. Yes

\section{Negative Affect (towards the child)}

Directing negative affect toward the child; or making fun of the child or putting the child down (e.g., "You're such a baby."; scowls; yelling; displays of anger).

0. No

1. Yes

\section{Engagement}

Focus on the parents' actions and displays of responsiveness during the interaction with the child. Included are displays of responsiveness, initiation, and cooperation.

1. None. Parent ignores the child or does not interact with the child during the interval. This includes doing something else (looking at a magazine or their phone).

2. Minimal. Parent responds, initiates contact, or interacts with the child (verbal or physical). The interaction between mother and child is 1-3 seconds in duration.

OR the parent only watches the child during the interval/for the majority of the interval. Conversation can be counted as engagement.

3. Parent is responsive to the child and initiates contact (verbal or non-verbal) for 4-6 seconds. Conversation can be counted as engagement. 
4. Parent is engaged with/playing with the child for majority of the interval ( 7 seconds or greater). The parent initiates contact and responds to the child. Conversation can be counted as engagement.

\section{Intrusiveness/Control}

Intrusive, insensitive interaction is definitely not child-centered but mother-centered. It $i$ not uncommon for intrusive mothers to verbalize their task-oriented or camera-oriented concerns which supersede the interests of the child. Negative affect or comments because the child isn't doing what the mother wants are indicative of lack of sensitivity and may accompany overcontrolling behavior.

The prototypic intrusive mother imposes her agenda on the child despite signals from the child that a different activity, level, or pace of interaction is needed. High arousal, vigorous physical interaction, or at rapid pace are not, by themselves, indicative of intrusive over-stimulation--if the child responds positively with sustained interest and is not engaging in defensive behaviors. It is when the child's gaze averts, turns away, or expresses negative affect and mother continues or escalates her activity that intrusive behavior is evident. Over-stimulation is also apparent when mother does not allow the child a "turn" or an opportunity to respond at his/her pace. Some intrusive mothers persist in demonstrating toys to the child long after they have gained the child's interest and the child obviously wants to manipulate the toy him/herself. These mothers appear unable to relinquish control of the interaction in order to facilitate the child's exploration or regulation of the activity. Another controlling, intrusive behavior is displayed by mothers who overwhelm the child with a rapid succession of toys or approaches without paying attention to the child's responses or without allowing him/her time to react to one before going on to another. Very commonly seen intrusive behavior is mothers' tendency to lose interest in a toy before the child does and either remove the toy or distract the child's attention to a new one when the child has not lost interest in what s/he was doing. (Basically, mother is bored so it's time to move on to something else--definitely evidence that her agenda is being addressed, not the child's.)

\section{Specific behaviors characterizing intrusive. over-controlling interaction:}

--failing to modulate behavior that the child turns away from, defends against, or expresses negative affect toward

--offering a continuous barrage of stimulation or toys, over-whelming the child rather than observing his/her reaction

--not allowing the child to influence the pace or focus of play or interaction by ignoring what the child shows interest in or by presenting a new toy while the child is still focused on another

--taking away objects while the child still appears interested (mother's attention span seems shorter than the child's)

--not allowing the child to handle toys he/she reaches for

--pulling the child's hand(s) off objects he/she is holding

--intrusive physical manipulations, such as grabbing the child's face and moving it back when the child has turned away

--making the child manipulate something, unless the child gives has a positive response; this behavior is over-controlling when it involves an object the child is able to control him/herself 
--controlling statements where mother is clearly redirecting child's attention away from their preferred activity.

--stepping in verbally or behaviorally when not asked for help

1. None observed

2. Low, one instance

3. Moderate, more than one instance of the behaviors above or one prolonged or intense instance.

4. High, mother is extremely intrusive or over-controlling 


\section{Appendix B \\ Parent Attitude/Behavior Questionnaire}

Instructions: In the following items, please indicate on a scale from 1 (very unlikely) to 7 (very likely) the likelihood that you would respond in the ways listed for each item. Please read each item carefully and respond as honestly and sincerely as you can. For each response, please circle a number from 1-7.

\begin{tabular}{|c|c|c|c|c|c|c|}
\hline $\begin{array}{l}1 \\
\text { Very Unlikely }\end{array}$ & 2 & 3 & $\begin{array}{c}4 \\
\text { Medium }\end{array}$ & 5 & 6 & $\begin{array}{c}7 \\
\text { Very Likely }\end{array}$ \\
\hline
\end{tabular}

1. If my child becomes angry because he/she is unable to go to his/her friend's birthday party, I would:

a. send my child to his/her room to cool off

1234567

b. get angry at my child

1234567

c. help my child think about ways that he/she can still be with

friends (e.g., invite some friends over after the party)

1234567

d. tell my child not to make a big deal out of missing the party

1234567

e. encourage my child to express his/her feelings of

anger and frustration

1234567

f. soothe my child and do something fun with him/her to make

him/her feel better about missing the party

1234567

g. Any other reaction?

2. If my child breaks his/her new bike, and then gets upset and cries, I would:

a. remain calm and not let myself get anxious

b. comfort my child and try to get him/her to forget

about the accident

1234567

1234567

c. tell my child that he/she is over-reacting

1234567

d. help my child figure out how to get the bike fixed

1234567

e. tell my child it's OK to cry

f. tell my child to stop crying or he/she won't be

allowed to ride his/her bike anytime soon

1234567

g. Any other reaction?

3. If my child loses some prized possession (stuffed animal) and reacts with tears, I would:

a. get upset with him/her for being so careless and

then crying about it

b. tell my child that he/she is over-reacting

c. help my child think of places he/she hasn't looked yet

1234567

d. distract my child by talking about happy things

1234567

e. tell him/her it's OK to cry when you feel unhappy

1234567

1234567

1234567

f. tell him/her that's what happens when you're not careful

1234567

g. Any other reaction?

4. If my child is afraid of injections and becomes quite shaky and teary while waiting for his/her turn to get a shot, I would:

a. tell him/her to shape up or he/she won't be allowed

to do something he/she likes to do (e.g., watch TV)

1234567

b. encourage my child to talk about his/her fears

1234567

c. tell my child not to make big deal of the shot

1234567

d. tell him/her not to embarrass us by crying

1234567 
e. comfort him/her before and after the shot

1234567

f. talk to my child about ways to make it hurt less

(such as relaxing so it won't hurt or taking deep breaths).

1234567

g. Any other reaction?

\begin{tabular}{|c|c|c|c|c|c|c|}
\hline $\begin{array}{l}1 \\
\text { Very Unlikely }\end{array}$ & 2 & 3 & $\begin{array}{c}4 \\
\text { Medium }\end{array}$ & 5 & 6 & $\begin{array}{c}7 \\
\text { Very Likely }\end{array}$ \\
\hline
\end{tabular}

5. If my child is going over to spend the afternoon at a friend's house and becomes nervous and upset because I can't stay there with him/her, I would:

a. distract my child by talking about all the fun he/she will

have with his/her friend

1234567

b. help my child think of things that he/she could do so that

being at the friend's house without me wasn't scary

(e.g., take a favorite book or toy with him/her)

1234567

c. tell my child to quit over-reacting and being a baby

1234567

d. tell the child that if he/she doesn't stop that he/she

1234567

won't be allowed to go out anymore

1234567

e. feel upset and uncomfortable because of my child's reactions

1234567

g. Any other reaction?

6. If my child is participating in some group activity with his/her friends and proceeds to make a mistake and then looks embarrassed and on the verge of tears, I would:

a. comfort my child and try to make him/her feel better

b. tell my child that he/she is over-reacting

1234567

c. feel uncomfortable and embarrassed myself

1234567

d. tell my child to straighten up or we'll go home right away

1234567

e. encourage my child to talk about his/her feelings

of embarrassment

1234567

f. tell my child that I'll help him/her practice so that

he/she can do better next time

1234567

g. Any other reaction?

1234567

7. If my child is about to appear in a recital or sports activity and becomes visibly nervous about people watching him/her, I would:

a. help my child think of things that he/she could do to get ready for his/her turn (e.g., to do some warm-ups and not to look at the audience)

b. suggest that my child think about something relaxing

so that his/her nervousness will go away

1234567

c. remain calm and not get nervous myself

1234567

d. tell my child that he/she is being a baby about it

1234567

e. tell my child that if he/she doesn't calm down, we'll

have to leave and go home right away

1234567

f. encourage my child to talk about his/her nervous feelings 
g. Any other reaction?

8. If my child receives an undesirable birthday gift from a friend and looks obviously disappointed, even annoyed, after opening it in the presence of the friend, I would:

a. encourage my child to express his/her disappointed feelings

1234567

b. tell my child that the present can be exchanged

for something the child wants

c. NOT be annoyed with my child for being rude

1234567

d. tell my child that he/she is over-reacting

1234567

e. scold my child for being insensitive to the

1234567

friend's feelings

1234567

f. try to get my child to feel better by doing something fun

1234567

g. Any other reaction?

$\begin{array}{llcccc}1 & 2 & 4 & 5 & 6 & 7 \\ \text { Very Unlikely } & & \text { Medium } & & & \text { Very Likely }\end{array}$

9. If my child is panicky and can't go to sleep after watching a scary TV show, I would:

a. encourage my child to talk about what scared him/her

1234

567

b. get upset with him/her for being silly

1234

567

c. tell my child that he/she is over-reacting

1234

567

d. help my child think of something to do so that he/she can get

to sleep (e.g., take a toy to bed, leave the lights on)

567

e. tell him/her to go to bed or he/she won't be allowed to

watch any more TV

1234

567

f. do something fun with my child to help him/her forget

about what scared him/her

1234

567

g. Any other reaction?

10. If my child is at a park and appears on the verge of tears because the other children are mean to him/her and won't let him/her play with them, I would:

a. NOT get upset myself

567

b. tell my child that if he/she starts crying

then we'll have to go home right away

567

c. tell my child it's OK to cry when he/she feels bad

567

d. comfort my child and try to get him/her to think about

something happy

1234

567 
e. help my child think of something else to do

567

f. tell my child that he/she will feel better soon

567

g. Any other reaction?

11. If my child is playing with other children and one of them calls him/her names, and my child then begins to tremble and become tearful, I would:

a. tell my child not to make a big deal out of it

567

b. feel upset myself

567

c. tell my child to behave or we'll have to go home right away

567

d. help my child think of constructive things to do when

other children tease him/her (e.g., find other things to do)

567

e. comfort him/her and play a game to take his/her mind off

the upsetting event

567

f. encourage him/her to talk about how it hurts to be teased

567

g. Any other reaction?

12. If my child is shy and scared around strangers and consistently becomes teary and wants to stay in his/her bedroom whenever family friends and their children come to visit, I would:

a. help my child think of things to do that would make meeting

my friends less scary (e.g., to take a favorite toy with

him/her when meeting my friends)

567

b. tell my child that it is OK to feel nervous

567

c. try to make my child happy by talking about the fun

things we can do with our friends

567

d. feel upset and uncomfortable because of my child's reactions

567

e. tell my child that he/she must stay in the living room and visit with our friends

567

f. tell my child that he/she is being a baby

567

g. Any other reaction?

$\begin{array}{lllcccc}1 & 2 & 3 & 4 & 5 & 6 & 7 \\ \text { Very Unlikely } & & & \text { Medium } & & & \text { Very Likely }\end{array}$


13. It is $\mathbf{1 5}$ minutes until dinner is ready. Your child asks for a cookie because she/he is "starving." You explain that dinner will be ready in 15 minutes and that she/he will have to wait until then. Your child yells and stomps his or her feet continuously. I would:

a. punish him/her for his/her behavior

567

b. get angry for his/her overreaction

567

c. tell my child that he/she is over-reacting

567

d. help my child think of something to do so that he/she can get keep occupied until dinner

567

e. tell my child that it's o.k. to feel angry, but s/he will have to wait for dinner

567

f. comfort my child by offering an alternate healthy snack (e.g., carrots)

567

g. Any other reaction?

14. You and your child are in a toy store. Your child asks you to buy him/her a new toy. You tell your child no, that she/he just received several new toys at her/his birthday party, and then you go to leave the store. Your child throws her/himself onto the floor kicking and screaming, yelling that she/he wants the toy. Your child will not leave the store. I would:

a. NOT get upset myself

1234

567

b. tell my child that if he/she will be punished when they get home

1234

567

c. tell my child it's OK to be angry, but they need to calm down

567

d. comfort my child and suggest to him/her how to calm down (e.g., count to five; deep breaths) 1234

567

e. distract my child by reminding him/her of another fun activity

s/he'll be doing later in the day/week

567

f. tell my child to stop acting like a baby

567

g. Any other reaction?

15. You've moved into a new neighborhood, and your child is invited to a birthday party being held for the child next door. You take your child to the party and stay awhile. You notice that your child looks very nervous and uncomfortable, and is keeping to her/himself.

a. tell my child not to make a big deal out of it

567

b. feel upset myself and uncomfortable because of my child's reactions

567

c. tell my child that $\mathrm{s} /$ he must remain at the party or they will be punished

567

d. help my child think of constructive things to do to feel more comfortable

567

e. comfort my child and tell him/her it's okay

1234

567

f. tell my child it's OK to be nervous

567

g. Any other reaction? 
16. Your child has a race with friends in the neighborhood, comes in first, and is very excited. When you get home, for a long time, your child continues to jump around gleefully and exclaim to you about her/his victory.

a. Encourage him/her to celebrate

567

b. tell my child that it is OK to feel happy

1234

567

c. point out my child's accomplishment, and tell him/her I am proud of him/her

567

d. feel uncomfortable because of my child's jubilant behavior

1234

567

e. tell my child that it's not that big of a deal, and to calm down

1234

567

f. tell my child to calm down or they'll get a time out

1234

567

g. Any other reaction?

17. It is your sister's birthday and she has invited the whole family to celebrate by going out for dinner. The restaurant she has chosen is rather elegant and formal. During the dinner your child exuberantly jumps out of his/her chair and shouts, "Happy birthday, Auntie!"

a. Encourage him/her to celebrate

1234

567

b. tell my child that it is OK to feel happy

1234

567

c. point out that my child's reaction was thoughtful, and tell him/her I am proud of him/her

1234

567

d. feel uncomfortable because of my child's jubilant behavior

1234

567

e. help my child to calm down by finding something else for them to do

1234

567

f. tell my child to calm down or they won't get any birthday cake

1234

567

g. Any other reaction?

\section{When your child displays ANGER how does it make you feel?}

\begin{tabular}{|c|c|c|c|c|c|}
\hline $\begin{array}{l}1 \\
\text { Not at all }\end{array}$ & 3 & $\begin{array}{c}4 \\
\text { Quite a bit }\end{array}$ & 5 & 6 & $\begin{array}{c}7 \\
\text { Extremely }\end{array}$ \\
\hline $\begin{array}{l}\text { How angry? } \\
\text { How disgusted? } \\
\text { How anxious? } \\
\text { How happy? } \\
\text { How sad? }\end{array}$ & & & & & 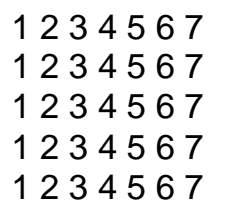 \\
\hline $\begin{array}{l}1 \\
\text { Rarely }\end{array}$ & 3 & $\begin{array}{c}4 \\
\text { Sometimes }\end{array}$ & 5 & 6 & $\begin{array}{l}7 \\
\text { Always }\end{array}$ \\
\hline
\end{tabular}

How often does your child need to be reminded to control his/her anger?

When you remind your child to control his/her anger, how

often are they able to control it? 
When your child displays FEAR/ANXIETY how does it make you feel?

\begin{tabular}{|c|c|c|c|c|c|c|}
\hline $\begin{array}{l}1 \\
\text { Not at all }\end{array}$ & 2 & 3 & $\begin{array}{c}4 \\
\text { Quite a bit }\end{array}$ & 5 & 6 & $\begin{array}{c}7 \\
\text { Extremely }\end{array}$ \\
\hline $\begin{array}{l}\text { How angry? } \\
\text { How disgusted? } \\
\text { How anxious? } \\
\text { How happy? } \\
\text { How sad? }\end{array}$ & & & & & & $\begin{array}{l}1234567 \\
12334567 \\
1234567 \\
1234567 \\
1234567\end{array}$ \\
\hline $\begin{array}{l}1 \\
\text { Rarely }\end{array}$ & 2 & 3 & $\begin{array}{c}4 \\
\text { Sometimes }\end{array}$ & 5 & 6 & $\begin{array}{l}7 \\
\text { Always }\end{array}$ \\
\hline
\end{tabular}

How often does your child need to be reminded to control his/her fear/anxiety?

1234567

When you remind your child to control his/her fear/anxiety, how

often are they able to control it?

1234567

When your child displays SADNESS how does it make you feel?

\begin{tabular}{|c|c|c|c|c|c|}
\hline $\begin{array}{l}1 \\
\text { Not at all }\end{array}$ & 3 & $\begin{array}{c}4 \\
\text { Quite a bit }\end{array}$ & 5 & 6 & $\begin{array}{c}7 \\
\text { Extremely }\end{array}$ \\
\hline $\begin{array}{l}\text { How angry? } \\
\text { How disgusted? } \\
\text { How anxious? } \\
\text { How happy? } \\
\text { How sad? }\end{array}$ & & & & & $\begin{array}{l}12344567 \\
12234567 \\
12345667 \\
1234567 \\
1234567\end{array}$ \\
\hline $\begin{array}{l}1 \\
\text { Rarely }\end{array}$ & 3 & $\begin{array}{c}4 \\
\text { Sometimes }\end{array}$ & 5 & 6 & $\begin{array}{l}7 \\
\text { Always }\end{array}$ \\
\hline
\end{tabular}

How often does your child need to be reminded to control his/her sadness?

1234567

When you remind your child to control his/her sadness, how

often are they able to control it?

1234567

When your child displays HAPPINESS how does it make you feel?

\begin{tabular}{|c|c|c|c|c|c|}
\hline 1 & 3 & $\begin{array}{c}4 \\
\text { Quite a bit }\end{array}$ & 5 & 6 & $\begin{array}{c}7 \\
\text { Extremely }\end{array}$ \\
\hline $\begin{array}{l}\text { How angry? } \\
\text { How disgusted? } \\
\text { How anxious? } \\
\text { How happy? } \\
\text { How sad? }\end{array}$ & & & & & $\begin{array}{l}1234567 \\
1234567 \\
1234567 \\
1234567 \\
1234567\end{array}$ \\
\hline $\begin{array}{l}1 \\
\text { Rarely }\end{array}$ & 3 & $\begin{array}{c}4 \\
\text { Sometimes }\end{array}$ & 5 & 6 & $\begin{array}{l}7 \\
\text { Always }\end{array}$ \\
\hline
\end{tabular}


How often does your child need to be reminded to control his/her happiness?

1234567

When you remind your child to control his/her happiness, how

often are they able to control it?

1234567

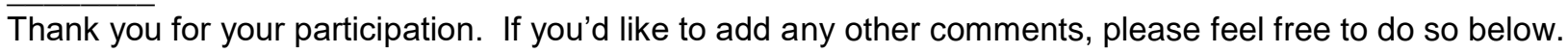
However, please refrain from using names, or any other identifiable information in your comments. 


\section{Appendix C}

\section{PRE-SCHOOL CHILDREN'S BEHAVIOR QUESTIONNAIRE}

\section{Almos Rarel Sometime Often Almos Don't}

1. Restless - runs about or jumps up and down, doesn't keep still.

2. Squirmy, fidgety child.

3. Destroys own or other's belongings.

4. Fights with other children.

5. Not much liked by other children.

6. Worries about things.

7. Tends to do things on his/her own, is rather

8. Irritable, quick to "fly off the handle".

9. Appears miserable, unhappy, tearful, or Nintrannan 10. Has twitches, mannerisms, or tics of his/her 11. Bînês nails or fingers.

12. Is disobedient.

13. Can't concentrate or attend for long.

14. Tends to be fearful or afraid of new things or new situations.

15. Fussy, wants things to be "just right", or 16. "Tells lies.

17. Is kind, loving with other children.

18. Is withdrawn with other children.

19. Shares toys, belongings with other children.

1

2

$$
1
$$

1

1

1

\section{1}

\section{1}

1

\section{(1)}

(1)

(1)

1

(1)

1

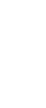

1

1

2


20. Bullies other children.

12

2

3

$4 \quad 5 \quad 6$

This questionnaire consists of a series of descriptions of behavior often shown by preschoolers. For each statement, please circle the number which best describes this child's recent and current behaviour (within the past 6 months). Please try to answer every item. If you really can't answer an item, circle "Don't know". Try not to spend too much time on any one question. 
21. Inattentive, doesn't notice what is happening. 22. Doesn't share toys.

23. Cries easily.

24. Blames others.

25. Gives up easily.

26. Does not consider the feelings of others.

27. Imaginative, creative.

28. Kicks, bites, or hits children.

29. Stares into space.

30. Has temper tantrums.

31. Disturbs others' ongoing activities (eg. another child's play).

32. Says nobody likes him or her.

33. Is aggressive toward people or objects.

34. Shows anxiety about being with a group of 35. Follows your instructions.

36. Attempts household tasks before asking for your 37. Áttends to your instructions.

38. Prefers to play alone than with other children.

39. Puts away toys or other household property (either with or without being asked).

40. Receives criticism well.

41. Follows household rules.

42. Is disturbed by change.

43. Has fun, displays peak positive affect.

44. Likes to go out (e.g., play dates).

45. When out, eager to return home quickly.

46. Is affectionate.

47. Is anxious.

48. Responds positively to affection from others.

49. Refuses active games.

50. Cries for long periods.

51. Is slow-moving.

52. Is moody.

\section{3}

3

3

3

3

3

3

3

3

3

3

3

3

3

3

3

3

3

3

4

4

5

5

5

5

5

5

\section{5}

5

5

5

5

5

5

5

5

5

5

5

5

3

3

3

3

3

3

3

3

3

3

3

3

3
6

6

6

6

6

6

6

6

6

6

6

6

6

6

6

6

6

6

6

6

6

6

6

6

6

6

6

6

6

6

6

6 
Almos Rarel Sometime Often Almos Don't

53. Sulks.

54. Looks tense (e.g., furrowed eyebrows/forehead).

55. Speaks to people (in addition to family) when outside the home.

56. Resists sleeping alone.

57. Has difficulty falling asleep.

58. Wakes up during the night (e.g., bad dreams).

59. Shows interest in his/her surroundings.

60. Has irritable or cranky moods.

61. Gets upset over little things.

62. Shows significant changes in his/her appetite for fond

63. Whines.

64. Has easily hurt feelings.

65. Is unsure, indecisive.

66. Avoids eye contact.

67. Whimpers.

68. Clings to adults.

69. Gets distracted, has a short attention span.

70. Watches other children play rather than join in.

71. Seems nervous (e.g., foot-tapping, nail-biting, hair-pulling).

72. Sucks his/her thumb or finger (when awake).

73. Is easily disappointed.

74. Seems lonely.

75. Trembles.

1

1

1

2

2

2

1

1

1

1

1

1

1

\section{1}

1

1

1

1

12

12

12

1

1

1

2

1

1

1

1
3

3

3

4

4

4

3

3

3

3

3

3

3

3

3

3

3

3

3

3

3

3

4

3

3

3

3

4

4

4

4

4

4$$
4
$$

4

4

4

4

4

4

4

4

4

4

4

4

4
5

6

6

6

$4 \quad 5$

\section{6}

6

6

6

6

6

6

6

6

6

6

6

6

6

6

6

6

6

6

6 


\section{Almos Rarel Sometime Often Almos Don't}

76. Displays fear of:

medical procedures (injections, throat swabs).

going to child care/kindergarten.

animals.

heights.

surprise toys (jack-in-the-box, masks).

illness, dirt or germs.

loved ones dying.

going to the toilet.

imaginary creatures (e.g., ghosts, monsters).

strangers.

the dark.

separation from parents.

being alone.

loud noises (e.g., trains, thunder, vacuum

other

\begin{tabular}{lll}
\hline & 1 & 2 \\
& 1 & 2
\end{tabular}

2

2

2

2

2

2

2

2

1

\section{1}

$$
1
$$

\section{1}

12

12

\section{1}



77. Has physical complaints:

aches, pains.

dizziness, headaches, "funny head".

nausea, vomiting, stomach aches, "funny

frequent urination or diarrhoea.

intermittent cold or eczema.

78. Looks guilty about his/her behaviour.

79. Seems to feel unloved.

80 . Is self-conscious.

81. Makes friends easily.

3
3
3
3
3
3
3
3
3
3
3
3
3
3
3
3

3
3
3
3

4

4

4

4

4

4

4

4

4

4

4

4

4

4

4

$4-5$

$4 \quad 5$

4

5

4

4

4

4

4

4

4

4

4

4

6

6

6

6

6

6

6

6

6

6

6

6

6

6

6

6 
82. Looks embarrassed.

83. Looks ashamed.

$\begin{array}{lll}1 & 2 & 3 \\ 1 & 2 & 3 \\ 1 & 2 & 3 \\ 1 & 2 & 3 \\ 1 & 2 & 3 \\ 1 & 2 & 3\end{array}$

3
3
3
3
3
3

$\begin{array}{lll}4 & 5 & 6 \\ 4 & 5 & 6 \\ 4 & 5 & 6 \\ 4 & 5 & 6 \\ 4 & 5 & 6 \\ 4 & 5 & 6\end{array}$
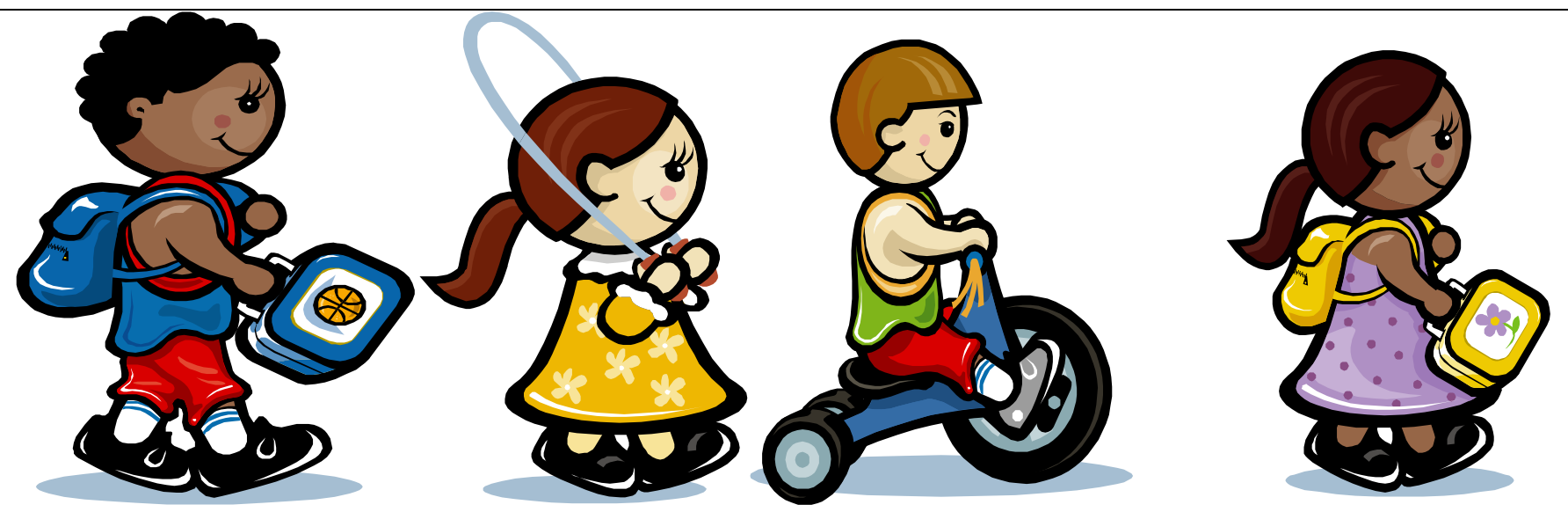

Almos Rarel Sometime Often Almos Don't

88. Feels jealous.

89. Is sensitive to criticism.

90. Do you consider this child to have behaviour problems?
1

1

1
2

2

2
3

3

3

4

4

4

5
6

6

6 